\section{(6) OPEN ACCESS}

\title{
Antibodies against carbamylated proteins are present in primary Sjögren's syndrome and are associated with disease severity
}

\author{
Brith Bergum, ${ }^{1}$ Catalin Koro, ${ }^{1}$ Nicolas Delaleu, ${ }^{1}$ Magne Solheim, ${ }^{2}$ Annelie Hellvard, ${ }^{1,3}$ \\ Veronika Binder, ${ }^{1}$ Roland Jonsson, ${ }^{1}$ Valeria Valim, ${ }^{4}$ Daniel $S$ Hammenfors, ${ }^{5}$ \\ Malin $\mathrm{V}$ Jonsson, ${ }^{1,6}$ Piotr Myde $^{1,3}$
}

Handling editor Tore K Kvien

- Additional material is published online only. To view please visit the journal online (http://dx.doi.org/10.1136/ annrheumdis-2015-207751)

For numbered affiliations see end of article.

Correspondence to Dr Piotr Mydel, Broegelmann Research Laboratory, Department of Clinical Science, University of Bergen, The Laboratory Building, 5th floor, Bergen N-5021, Norway; piotr. mydel@k2.uib.no

$\mathrm{BB}, \mathrm{CK}$ and ND contributed equally.

Received 8 April 2015 Revised 17 August 2015 Accepted 19 August 2015 Published Online First 8 September 2015

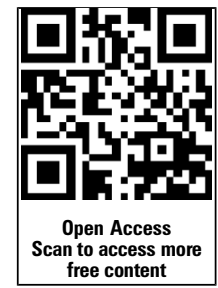

CrossMark

To cite: Bergum B, Koro $C$, Delaleu N, et al. Ann Rheum Dis 2016;75:1494-1500.

\section{ABSTRACT}

Objectives Herein, we investigate the presence and prognostic value of autoantibodies against carbamylated proteins (anti-CarP) in the serum of patients with primary Sjögren's syndrome (pSS).

Patients and methods Serum levels of anti-CarP antibodies were measured in Norwegian patients with pSS $(n=78)$ and corresponding controls $(n=74)$ using ELISA and analysed in relation with exocrine gland function, degree of salivary gland inflammation, signs of ectopic germinal centre (GC) formation and immunological markers. For univariate comparisons, the Mann-Whitney $U$ test and $\chi^{2}$ or Fisher's exact tests were used. Correlations were assessed with Spearman's rank testing. Multivariate regression analyses were used to assess the effect of anti-CarP positivity on clinical manifestations.

Results of the patients with pSS, $27 \%$ were positive for anti-CarP IgG antibodies. Levels of anti-CarP correlated positively with total $\lg G$, $\lg M$, rheumatoid factor and $\beta 2$-microglobulin. Importantly, after adjusting for confounding factors, patients positive for anti-CarP had significantly higher focus score. Furthermore, positive anti-CarP status coincided with 9.2-fold higher odds of having developed GC-like structures in the minor salivary glands. As a patient group considered having worse disease outcome, individuals with ectopic GC-like structures also presented with significantly higher levels of anti-CarP antibodies.

Conclusions Presence of anti-CarP in patients with pSS is strongly associated with increased focal lymphocytic infiltration, formation of ectopic GC-like structures in minor salivary glands, and diminished salivary gland function. Even taking into consideration our relatively small cohort we believe that anti-CarP antibodies offer new possibilities for identifying patients with more active disease and at risk of developing additional comorbidity.

\section{INTRODUCTION}

Subsequent to translation, nearly all proteins undergo post-translational modifications that affects their function. ${ }^{1}$ Protein carbamylation is a cyanatedependent, non-enzymatic conversion of lysine residues and $\mathrm{N}$-terminal amino groups to $\varepsilon$-carbamyl-lysine (homocitrulline) and $\alpha$-carbamyl amino acids, respectively. Introduction of neutral residues affects the charge distribution within the polypeptide chain. This can result in impairment or loss of a protein's function. ${ }^{2-5}$ Since urea, a by-product of protein metabolism, and cyanate comprise an equilibrium pair, the level of protein carbamylation is markedly increased in renal insufficiency, leading to chronic uraemia. ${ }^{6}{ }^{7}$ Interestingly, recent studies demonstrated a novel pathway connecting carbamylation with inflammation via the activation of myeloperoxidase (MPO). MPO is a haem peroxidase released by activated neutrophils. It catalyses the formation of cyanate from thiocyanate in the presence of hydrogen peroxide, leading to homocitrulline formation. ${ }^{8} 9$ This discovery attracted attention to carbamylation in the context of chronic inflammatory and autoimmune diseases.

It is important to remember that antibodies can be a double-edged sword for the host. In addition to their protective effect against pathogens, some individuals produce self-reactive antibodies that contribute to tissue damage in a variety of autoimmune diseases. In the recent years, autoantibodies against post-translationally modified proteins have gained considerable interest in the field of rheumatoid arthritis (RA). The antibodies directed against citrullinated proteins (ACPAs) have become a specific early serological marker of the disease and crucial for patient stratification. ${ }^{10}$ In addition to citrulline, carbamyl adducts have also been shown to act as neoepitopes in $\mathrm{RA}^{11}$ and juvenile idiopathic arthritis ${ }^{12}$ resulting in the production of antibodies specifically targeting carbamylated residues (anti-CarP). In an RA cohort and an arthralgia cohort, the presence of anti-CarP correlated with joint destruction and was reported to be predictive of RA development, independent of the presence of anticyclic citrullinated peptide antibodies. $^{13} 14$

Primary Sjögrens's syndrome (pSS) is an autoimmune, chronic inflammatory disease of unknown aetiology. Like most autoimmune diseases, pSS is multifactorial, and genetic predispositions and environmental factors are assumed to be pivotal in disease development. The prevalence of pSS is estimated at approximately $0.09-0.72 \%$ of the general population. ${ }^{15}$ As pSS in characterised by progressive infiltration of mononuclear cells into lacrimal and salivary glands, most patients with pSS suffer from severe symptoms of ocular and oral dryness (keratoconjunctivitis sicca and xerostomia, respectively) and functional impairment of the 
respective glands. ${ }^{16-19}$ Severe disease outcomes also include disabling fatigue and development of non-Hodgkin's lymphoma. The prevalence of the latter condition is approximately 16 times more common in patients with pSS as compared with the general population. To date, all therapies thus far tested have been ineffective in reversing the course of pSS. ${ }^{20} 21$

Patients with pSS may present with a variety of autoantibodies. Circulating antinuclear antibodies are present in up to $90 \%$ of the patients with pSS, of which antibodies reactive against the ribonucleoprotein antigens Ro/Sjögren's syndrome A antigen (SSA) and La/Sjögren's syndrome B antigen (SSB) are of diagnostic value 2223 and may be detectable in the serum several years prior to the diagnosis of $\mathrm{pSS}^{24}$ In addition, several other autoantibodies have been associated with the disease, including antibodies against the Fc portion of $\operatorname{IgG}$ (rheumatoid factor; RF), muscarinic acetylcholine type 3 receptor, carbonic anhydrase, alpha-fodrin, and, to a lesser extent, cyclic citrullinated peptide. $^{25-27}$ Over the last decade, multiple studies have delineated the importance of autoantibodies as a clinical utility; it remains unknown, however, whether any of the autoantibodies have a direct pathogenic potential or if they merely participate in a secondary response to salivary glands that are already damaged by another process.

In summary, carbamylated proteins are present in inflammatory foci, and there is mounting evidence that post-translational modifications may be pivotal in breaching immune tolerance against self-proteins and driving autoantibody production. This is, to our knowledge, the first study investigating the prevalence of antibodies against carbamylated proteins in patients with pSS. In addition, we assessed whether anti-CarP antibodies may serve as an early biomarker by systematically evaluating their association with clinical characteristics, disease progression and severity.

\section{MATERIALS AND METHODS Study sample}

The Bergen cohort comprises of patients diagnosed with pSS $(n=84)$ who had been consecutively recruited and evaluated at the Department of Rheumatology, Haukeland University Hospital in Bergen, Norway between 2011 and 2015. Patients diagnosed with additional autoimmune diseases or lymphoma $(n=6)$ were excluded; 78 patients were considered eligible for the study. The patients fulfilled the American-European Consensus Group criteria for classification of $\mathrm{pSS}^{22}$ and had their medical history recorded. Sex-matched and approximately age-matched healthy controls $(n=74)$ were recruited from the same geographical area through the Haukeland University Hospital Blood Bank. All patients provided written informed consent.

\section{Detection of anti-CarP antibodies}

To investigate the levels of anti-CarP antibodies in serum, a modified ELISA protocol developed by Shi et al ${ }^{11}$ was used. Fetal calf serum (FCS) was carbamylated by incubation with a final concentration of $1 \mathrm{M}$ potassium cyanate in distilled water for $48 \mathrm{~h}$ at $37^{\circ} \mathrm{C}$. Following incubation, the potassium cyanatecontaining buffer was exchanged with water using Float-a-lyzer G2 (5 kDa) (Spectrum Labs, Breda, the Netherlands). Native and carbamylated FCS (cFCS) was coated on Nunc Maxisorp 96-well plates (Thermo Scientific, Oslo, Norway) overnight at a concentration of $10 \mu \mathrm{g} / \mathrm{mL}$ in $0.1 \mathrm{M}$ carbonate-bicarbonate buffer. Following washing $(0.05 \%$ Tween in phosphate buffered saline) and blocking (1\% bovine serum albumin in phosphate buffered saline), the wells were incubated with serum at a 1:50 dilution in duplicate overnight at $4^{\circ} \mathrm{C}$ on ice. Bound $\operatorname{IgG}$ was detected after incubation with an horseradish peroxidaseconjugated rabbit antihuman IgG antibody (P0214, Dako, Oslo, Norway) for $3.5 \mathrm{~h}$ at $4^{\circ} \mathrm{C}$ on ice. After the last wash, horseradish peroxidase enzyme activity was detected using orthophenylenediamine tablets (Dako). The optical density was measured at $450 \mathrm{~nm}$ using an $\mathrm{E}_{\max }$ precision microplate reader (Molecular Devices, Sunnyvale, California, USA) and analysed using Soft Max Pro software. To ensure that all results would be comparable, all samples were analysed simultaneously. The background signal of FCS was subtracted from the signal of cFCS in order to analyse the specific anti-CarP reactivity. Samples yielding optical density values more than two SDs above the mean of the anti-CarP measurement of the healthy controls were considered positive for anti-CarP antibodies.

\section{Statistical analysis}

The Mann-Whitney $U$ test was used to compare the anti-CarP levels between patients with pSS and the healthy controls. Outliers, identified using the robust regression and outlier removal method $(\mathrm{Q}=1 \%)$, were excluded from the analysis. For univariate comparisons between anti-CarP-positive and anti-CarP-negative patients, the Mann-Whitney U test was used for continuous data and the $\chi^{2}$ or Fisher's exact test, as appropriate, were used for categorical data. Correlations were assessed with Spearman's rank testing. Spearman's partial correlations were modelled to adjust for age, disease duration and total IgG. To evaluate the effect of anti-CarP positivity on clinical manifestations, multivariate Poisson regression analysis was used for analysis of the focus score, and multivariate logistic regression was used for analysis of the presence of germinal centre (GC)-like structures in minor salivary glands. All of the analyses were two-tailed and a $p$ value $<0.05$ was considered statistically significant. Statistical analyses were performed using Prism V.5 or 6 (GraphPad Software), SPSS statistics V.22 and SAS statistical software V.9.4.

\section{RESULTS}

\section{Demographic and clinical features}

Serum from patients with pSS $(n=78)$ and healthy controls $(n=74)$ was analysed. Both cohorts were predominantly comprised of women $(93.6 \%$ of the patients with pSS and $93.2 \%$ of controls). The median ages of the patients with pSS and controls were 65 years (range, 31-84) and 56 years (range, 40-70), respectively. At the time of serum collection 18 (23\%) were being treated with methotrexate or hydroxychloroquine. Sixteen patients $(20.5 \%)$ were being treated with corticosteroids. A minor salivary glands biopsy was taken from 68 patients. The focus score was available for 66 patients, and information on the presence of ectopic GC-like structures in the salivary glands was available for 68 patients. Additionally, 66 (84.6\%) patients reported extraglandular involvement. All information on the pSS cohort has been summarised in the online supplementary table S1.

\section{Anti-CarP antibody prevalence}

Anti-CarP antibodies were significantly higher in the pSS cohort as compared with the control cohort $(26.9 \%$ vs $6.8 \%$, respectively; $\mathrm{p}<0.0001$; figure 1 ). The levels of anti-CarP in the healthy controls are in line with previous reports. ${ }^{13} 14$

\section{Associations between clinical manifestations and anti-CarP seropositivity in patients with pSS}

Univariate analyses comparing patients with pSS according to their anti-CarP status established that anti-CarP seropositivity 




Figure 1 Antibodies against carbamylated fetal calf serum (cFCS) in healthy controls and patients with primary Sjögren's syndrome (pSS). The horizontal line in the box-and-whiskers plot indicates the median and the whiskers represent the minimum and maximum values in each group. The dashed line represents the cut-off value for patients considered positive for antibodies against carbamylated proteins, which was calculated as the mean plus two times the SD of the healthy controls. The statistical significance was evaluated by the Mann-Whitney U test. Anti-CarP, autoantibodies against carbamylated proteins.

was significantly associated with the following measures of pSS disease severity: higher focus scores $(p=0.005)$, presence of GC-like structures $(p=0.04)$ and reduced tear flow $(p=0.042)$. Whereas $71.4 \%$ of the anti-CarP-positive patients were positive for RF, the same was true for only $12.3 \%$ of the anti-CarP-negative patients. In line with this finding, anti-CarP antibody-positive patients had significantly higher titres of RF as compared with anti-CarP-negative patients $(p<0.0001)$. Furthermore, anti-CarP antibody-positive patients had increased levels of $\beta 2$-microglobulin $(p=0.002), \operatorname{IgG}(p=0.011), \operatorname{IgM}$ $(p=0.005)$. By contrast, neither extraglandular involvement $(p=1)$ nor levels of $C$ reactive protein $(p=0.4)$ were significantly associated with presence of anti-CarP antibodies (table 1).

We considered also the possibility that the use of therapeutic drugs might have affected the levels of serum markers in our patient cohort. ${ }^{28}$ However, the use of corticosteroids was very limited and should not have influenced the results. Among the disease-modifying antirheumatic drugs, most of the patients used hydroxychloroquine. We considered the possibility the use of hydroxychloroquines might have influenced the levels of RF, $\operatorname{IgM}$ and $\operatorname{IgG}^{29-32}$ and therefore anti-CarP antibody levels. Indeed, our results indicate that hydroxychloroquine may have an effect on the levels of anti-CarP $(p=0.016)$. However, due to the limited number of patients using this drug we believe that a larger study is needed to evaluate if the use of hydroxychloroquine will affect the concentration of circulating anti-CarP IgG.

The variables that were found to be significantly associated with the prevalence of anti-CarP at the univariate level were examined in pairwise correlation analyses. The correlation analyses confirmed that high levels of anti-CarP antibodies are conceding with focus score $(r=0.287, p=0.020)$, low stimulated salivary flow $(\mathrm{r}=-0.240, \mathrm{p}=0.039)$ and high serum levels of 32-microglobulin $(r=0.348, p=0.002)$, high $R F \quad(r=0.443$, $\mathrm{p}<0.0001)$, total $\operatorname{IgM}(\mathrm{r}=0.318, \mathrm{p}=0.005)$ and total $\operatorname{IgG}$ $(\mathrm{r}=0.320, \mathrm{p}=0.004)$. Importantly, after adjusting for total IgG, age and disease duration, significance was retained for all variables except stimulated salivary flow (table 2). In the context of exocrine gland function, anti-CarP levels did not correlate with reduced tear flow (data not shown).

\section{Multivariable analysis of focus score}

To assess the effect of anti-CarP levels on focus score a multivariate Poisson regression model was used. The model adjusted for the potential covariates age and disease duration. In addition, RF, antinuclear antibodies, anti-Ro/SSA and anti-La/SSB were included as confounders since these variables are associated with high focus score. ${ }^{33} 34$ As shown in table 3, anti-CarP positivity predicted increase in the average focus score with $69.4 \%$ regardless of the confounders included in the model $(p=0.026)$. It is, however, important to mention that each year of increased disease duration $(\mathrm{p}=0.001)$ and anti-La/SSB positivity $(\mathrm{p}=0.005)$ also predicted an increase in the average focus score $(3.1 \%$ and $99.1 \%$, respectively).

\section{Association between anti-CarP levels and GC-like structures}

Formation of GC-like structures within the salivary gland is emerging as a marker of disease progression and possibly worse clinical outcome. As shown in table 1, frequency of ectopic GC-like structures was $38.9 \%$ in anti-CarP seropositive patients with pSS compared with $14.0 \%$ in anti-CarP seronegative patients. To further calculate the association between the presence of anti-CarP and GC-like structures we compared the absolute levels of anti-CarP antibodies in patients positive and negative for ectopic GCs. In line with the previous findings, patients presenting GC-like structures in the minor salivary gland had significantly higher levels of circulating anti-CarP antibodies ( $p=0.027$; figure 2). This result led us to investigate a possible effect of anti-CarP positivity on the presence of GC-like structures. After adjusting for age and disease duration, $\mathrm{RF}$, anti-Ro/SSA and anti-La/SSB multivariate logistic regression modelling revealed that patients positive for anti-CarP had 9.2 times higher odds of having developed GC-like structures in the minor salivary glands as compared with anti-CarP negative patients $(p=0.019$; table 4$)$.

\section{DISCUSSION}

Understanding the role of autoantibodies and exploiting their value as biomarkers is of utmost importance for advancing the field of autoimmune diseases and improving patient care. As an example, the identification of ACPA as a specific marker and diagnostic tool for RA has enabled significant understanding of the pathogenesis of this disease due to its strong association with a more severe disease course. ${ }^{35-37}$ In SS, autoantibodies of different specificities have been associated with various clinical manifestations. The antibodies that are most well studied and integral to diagnosis of patients with SS, anti-Ro/SSA and anti-La/SSB, have been associated with earlier disease onset, rapid disease progression and increased prevalence for developing extraglandular manifestations. Furthermore, the presence of cryoglobulins is strongly correlated with development of lymphoma among patients with pSS. ${ }^{38}$

In this context, we generally detected anti-CarP antibodies in patients that presented with a more severe disease phenotype. Importantly, this apparent increase in disease activity included several key aspects of SS pathogenesis, ranging from the degree of chronic mononuclear cell inflammation and lymphoid organisation within the salivary glands, to the functional impairment indicated by decreased salivary secretion. Although one may only speculate about the exact mechanism underlying the formation of anti-CarP antibodies, it is now well documented that presence of MPO leads to increased protein carbamylation, ${ }^{39}$ possibly facilitating a breach in immune tolerance. Concordantly, the activity of circulating MPO is significantly 
Table 1 Associations with laboratory parameters in anti-CarP IgG-positive and IgG-negative patients with primary Sjögren's syndrome

\begin{tabular}{|c|c|c|c|}
\hline & Anti-CarP IgG positive $(n=21)$ & Anti-CarP IgG negative $(n=57)$ & $\mathrm{p}$ Value \\
\hline Women (\%) & $20(95.2)$ & $53(93.0)$ & 1 \\
\hline Age, median (range) years & $66(35-84)$ & $64(31-83)$ & 0.318 \\
\hline Disease duration, median (range) years & $20(1-40)$ & $21(1-50)$ & 0.394 \\
\hline Methotrexate, number (\%) & $1(4.7)$ & $3(5.3)$ & 1 \\
\hline Hydroxychloroquine, number (\%) & $0(0.0)$ & $14(24.6)$ & 0.016 \\
\hline Corticosteroids, number (\%) & $3(14.3)$ & $13(22.8)$ & 0.537 \\
\hline Rituximab, number (\%) & $0(0)$ & $1(1.8)$ & 1 \\
\hline Extraglandular involvement, number (\%) & $19(90.5)$ & $50(87.7)$ & 1 \\
\hline Focus score $\ddagger$, median (range) & $3(0-7)^{*}$ & $1(0-6) \uparrow$ & 0.005 \\
\hline Focus score $\geq 1$, number (\%) & $16(94.1)^{*}$ & 39 (79.6)ף & 0.246 \\
\hline GC-like structures present, number (\%) & $7(38.9) \dagger$ & $7(14.0)^{* *}$ & 0.040 \\
\hline Tear flow Shirmer's I test, median (range) $\mathrm{mm} / 5 \mathrm{~min}$ & $2.0(0-31.5)$ & $4.0(0-31.5)+\dagger$ & 0.042 \\
\hline Ocular dryness, $<5 \mathrm{~mm} / 5 \mathrm{~min}$ & $17(81.0)$ & $37(67.3)+\dagger$ & 0.130 \\
\hline Unstimulated salivary flow, median (range) $\mathrm{g} / 15 \mathrm{~min}$ & $0.4(0-2.4)$ & $1(0-4.3) \ddagger \ddagger$ & 0.213 \\
\hline Stimulated salivary flow, median (range) $\mathrm{g} / 5 \mathrm{~min}$ & $2.6(0-1.4)$ & $4.1(0-12.5) \ddagger \ddagger$ & 0.061 \\
\hline ESSDAI score, median (range) & $2(0-17) \S \S$ & $2(0-17)^{*}$ & 0.824 \\
\hline ESR, median (range) $\mathrm{mm} / \mathrm{h}$ & $26(4-62)$ & $20(4-58)$ & 0.058 \\
\hline ESR, high levels $\| \eta$, number (\%) & $10(47.6)$ & $16(28.1)$ & 0.104 \\
\hline CRP, median (range) $\mathrm{mg} / \mathrm{L}$ & $2(1-7)$ & $2(1-17)$ & 0.400 \\
\hline CRP high levels ( $\geq 5 \mathrm{mg} / \mathrm{L})(\%)$ & $3(14.3)$ & $11(19.3)$ & 0.748 \\
\hline C3, median (range) $\mathrm{g} / \mathrm{L}$ & $1.12(0.75-10.4)$ & $1.11(0.7-8.5)$ & 0.731 \\
\hline C3, low levels $(<0.83 \mathrm{~g} / \mathrm{L})$ number $(\%)$ & $3(14.3)$ & $3(5.3)$ & 0.335 \\
\hline $\mathrm{C} 4$, median (range) $\mathrm{g} / \mathrm{L}$ & $0.19(0.06-0.33)$ & $0.18(0.06-1.24)$ & 0.271 \\
\hline C4, low levels $(<0.13 \mathrm{~g} / \mathrm{L})$ number $(\%)$ & $6(28.6)$ & $6(10.5)$ & 0.092 \\
\hline $\mathrm{RF}$, median (range) IU/mL & $92(11-1040)$ & $11(11-239)$ & $<0.0001$ \\
\hline RF positive (>25 IU/mL) & $15(71.4)$ & $7(12.3)$ & $<0.0001$ \\
\hline Anti-Ro/SSA, number (\%) & $17(80.9)$ & $37(64.9)$ & 0.173 \\
\hline Anti-La/SSB, number (\%) & $10(47.6)$ & $18(31.6)$ & 0.190 \\
\hline ANA, number (\%) & $17(80.9)$ & $42(73.7)$ & 0.500 \\
\hline Anti-CCP, number (\%) & $2(9.5)$ & $1(1.8)$ & 0.193 \\
\hline IgA, median (range) g/L & $2.6(0.9-4.2)$ & $2.48(0.3-16.4)$ & 0.513 \\
\hline Elevated levels (>4.1 g/L), number (\%) & $2(9.5)$ & $4(7)$ & 0.658 \\
\hline IgG, median (range), g/L & $14.1(9.1-29.5)$ & $12.4(6.2-23.5)$ & 0.011 \\
\hline Elevated levels (>15.3 g/L), number (\%) & $8(38.1)$ & $12(21.1)$ & 0.658 \\
\hline IgM, median (range) g/L & $1.47(0.4-10.4)$ & $0.9(0.3-3.5)$ & 0.005 \\
\hline Elevated levels (>2.5 g/L) number (\%) & $1(4.8)$ & $2(3.5)$ & 1 \\
\hline$\beta 2$-microglobulin, median (range) $\mathrm{mg} / \mathrm{L}$ & $3.6(1.8-7.7)$ & $2.5(0-6.1)$ & 0.002 \\
\hline Elevated levels (>2 mg/L), number (\%) & $20(95.2)$ & $45(78.9)$ & 0.167 \\
\hline
\end{tabular}

Continuous data are expressed as the median (range). Categorical data are expressed as the absolute frequency (percentage).

The statistical significance was evaluated by the Mann-Whitney $U$ test for continuous data and the $\chi^{2}$ or Fisher's exact tests, as appropriate for categorical data. No adjustments have been made for multiple testing.

${ }^{*}$ Data missing for four patients.

tData missing for three patients.

$\ddagger$ Focus score indicates the number of inflammatory foci containing more than 50 mononuclear cells per $4 \mathrm{~mm}^{2}$ biopsy tissue.

IData missing for eight patients.

**Data missing for seven patents.

††Data missing for two patients.

$\ddagger \neq$ Data missing for three patients.

$\S \S$ Data missing for one patient.

I1|Age and gender-dependent.

ANA, antinuclear antibodies; anti-CCP, anticyclic citrullinated peptides; anti-CarP, autoantibodies against carbamylated proteins; Anti-Ro/SSA, antibodies against Ro/Sjögren's syndrome A antigen; Anti-La/SSB, antibodies against La/Sjögren's syndrome B antigen; C, complement component; CRP, C reactive protein; ESR, erythrocyte sedimentation rate; ESSDAI, the EULAR SS disease activity index; $\mathrm{GC}$, germinal centre; $\mathrm{RF}$, rheumatoid factor.

increased in patients with SS. ${ }^{40}$ Despite this obvious indication and the fact that MPO-dependent carbamylation and antiCarP antibodies has raised considerable interest in the context of inflammatory diseases including atherosclerosis and in particular $\mathrm{RA}^{8} 13394142$ this is, to our knowledge, the first study investigating the prevalence of antibodies against carbamylated proteins in patients with pSS.

Interestingly, the rate of patients in the pSS cohort that were seropositive for anti-CarP antibodies in this study (27\%) corresponds well with the proportion of ACPA-negative patients with 
Table 2 Correlation between serum levels of anti-CarP IgG and various laboratory parameters in patients with primary Sjögren's syndrome

\begin{tabular}{|c|c|c|c|c|}
\hline & \multicolumn{2}{|c|}{ Spearman's rank test } & \multicolumn{2}{|c|}{$\begin{array}{l}\text { Spearman partial } \\
\text { correlation* }^{*}\end{array}$} \\
\hline & $r$ & $\mathrm{p}$ Value & $\mathrm{R}$ & $p$ Value \\
\hline Stimulated salivary flow & -0.240 & 0.039 & -0.255 & 0.060 \\
\hline Focus score & 0.287 & 0.020 & 0.28 & 0.022 \\
\hline$\beta 2$-microglobulin & 0.348 & 0.002 & 0.23 & 0.048 \\
\hline $\mathrm{RF}$ & 0.443 & $<0.0001$ & 0.34 & 0.003 \\
\hline $\lg M$ & 0.318 & 0.005 & 0.28 & 0.014 \\
\hline $\lg G$ & 0.320 & 0.004 & & \\
\hline
\end{tabular}

All variables are presented as continuous data.

${ }^{*}$ Adjusted for lgG, age, and disease duration. Focus score indicates the number of proinflammatory foci containing $>50$ mononuclear cells per $4 \mathrm{~mm}^{2}$ biopsy tissue. Anti-CarP, autoantibodies against carbamylated proteins; RF, rheumatoid factor.

RA presenting these antibodies. In line with the previous reports we have not seen any cross-reactivity of anti-CarP antibodies towards citrullinated peptides and/or proteins. ${ }^{11}$ Only two anti-CarP positive and one anti-CarP negative patients were at the same time ACPA-positive. Recent studies showed presence of circulating antibodies against cFCS years before the development of RA, with a sensitivity ranging between $26 \%$ and $57 \%$. ${ }^{11} 13144344$ We were unable to see any connection between arthritis and the presence of anti-CarP antibodies in our cohort of patients with pSS using Fisher's exact test, which indicates that anti-CarP does not obviously associate with secondary arthritis.

Our results also show strong positive correlations between levels of anti-CarP antibodies and total IgG, IgM, RF and $\beta 2$-microglobulin, indicating that upregulation of anti-CarP occurs in the context of a generalised increase in B cell activity. It is important to mention that $29(37.2 \%)$ of the patients recruited to this study were classified with hypergammaglobulinemia, with elevated levels of at least one of the immunoglobulin isotypes. However, the possibility that the increased levels of anti-CarP antibodies were the sole result of increased IgG levels could be ruled out after adjusting for IgG in a partial correlation analysis. Seropositivity for anti-CarP and RF generally coincided, and the positive pairwise correlation between these two parameters was highly significant. However, this needs to be interpreted with caution due to the high number of patients in whom RF could not be detected ( $<11 \mathrm{IU} / \mathrm{mL})$.

Table 3 Multivariate Poisson regression analysis investigating the effect of anti-CarP IgG positivity on focus score

\begin{tabular}{lllll}
\hline & IRR & Std. Err & $\mathbf{p}$ Value & $\mathbf{9 5 \%}$ Cl of IRR \\
\hline Anti-CarP IgG & 1.694 & 0.402 & 0.026 & 1.064 to 2.696 \\
\hline Age & 1.010 & 0.009 & 0.285 & 0.991 to 1.029 \\
\hline Disease duration & 1.031 & 0.010 & 0.001 & 1.012 to 1.050 \\
\hline RF & 1.301 & 0.328 & 0.297 & 0.793 to 2.133 \\
\hline Anti-Ro/SSA & 0.593 & 0.173 & 0.074 & 0.334 to 1.051 \\
\hline Anti-La/SSB & 1.991 & 0.492 & 0.005 & 1.227 to 3.232 \\
ANA & 1.423 & 0.445 & 0.445 & 0.771 to 2.627
\end{tabular}

Anti-CarP IgG, RF, anti-Ro/SSA, anti-La/SSB and ANA are presented dichotomously. ANA, antinuclear antibodies; anti-CarP, autoantibodies against carbamylated proteins; Anti-Ro/SSA, antibodies against Ro/Sjögren's syndrome A antigen; Anti-La/SSB, antibodies against La/Sjögren's syndrome $B$ antigen; IRR, incidence rate ratio; RF, rheumatoid factor.

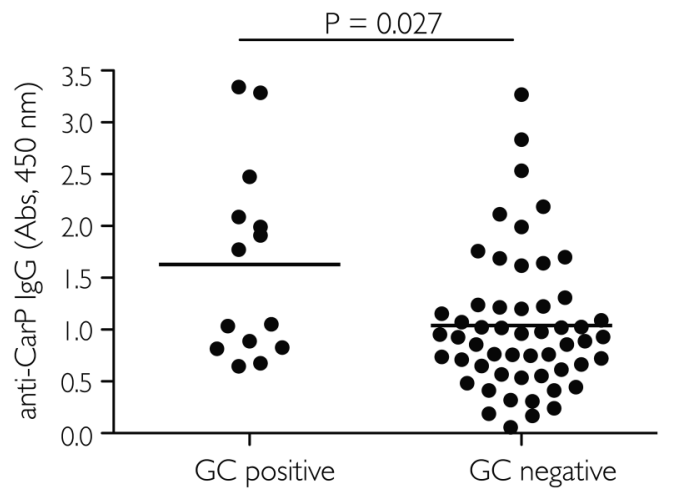

Figure 2 Levels of autoantibodies against carbamylated proteins (anti-CarP) antibodies in patients positive or negative for germinal centre (GC)-like structures in the minor salivary glands. The horizontal line indicates the median. The statistical difference was evaluated by the Mann-Whitney U test.

Indeed, increased mortality in patients with pSS seems strictly related to the increased risk of lymphoproliferative malignancy. ${ }^{45}$ In this context, it is important to remember that the presence of GC-like structures in the minor salivary glands appears to be a strong predictor for the development of lymphoma $^{46}$ and is associated with a more severe disease profile. ${ }^{47} 48$ Thus, our finding on an admittedly limited group of patients, that a positive anti-CarP status coincides with more than ninefold higher odds of presenting with GC-like structures suggests need for further studies evaluating anti-CarP as a prognostic biomarker of poor clinical outcome.

To add more weight to our findings we evaluated the presence of anti-CarP IgG antibodies in serum samples from two additional patient cohorts. Cohort 2 (online supplementary figure $\mathrm{S} 1 \mathrm{~A})$ represents a patient group recruited in Bergen (consecutive 2004-2009) and cohort 3 comprises samples collected from a Brazilian population (see online supplementary figure S1B). Indeed, the proportion of patients being seropositive for anti-CarP antibodies was relatively stable across these three cohorts. In cohort 2, $13(28.9 \%)$ out of 45 patients with pSS and $18(19.6 \%)$ out of 92 patients from cohort 3 were found positive for anti-CarP IgG antibodies. Corresponding to our findings for cohort 1, also the patients with SS comprised in these additional cohorts had significantly higher levels of anti-CarP antibody compared with healthy controls $(p=0.0006$ and $\mathrm{p}=0.016$ for cohorts 2 and 3 , respectively).

Table 4 Multivariate logistic regression analysis investigating the effect of anti-CarP IgG positivity on the presence of germinal centre-like structures

\begin{tabular}{lllll}
\hline & OR & SE & $\mathbf{p}$ Value & $\mathbf{9 5 \%} \mathrm{Cl}$ of OR \\
\hline Anti-CarP IgG & 9.245 & 0.946 & 0.019 & 1.448 to 59.044 \\
\hline Age & 1.037 & 0.033 & 0.273 & 0.972 to 1.105 \\
\hline Disease duration & 0.965 & 0.038 & 0.357 & 0.895 to 1.041 \\
\hline RF & 0.264 & 0.989 & 0.178 & 0.038 to 1.836 \\
\hline Anti-Ro/SSA & 1.204 & 1.035 & 0.857 & 0.158 to 9.155 \\
\hline Anti-La/SSB & 7.141 & 0.881 & 0.026 & 1.270 to 40.144
\end{tabular}

Anti-CarP IgG, RF, anti-Ro/SSA, and anti-La/SSB are presented dichotomously. Anti-CarP, autoantibodies against carbamylated proteins; Anti-Ro/SSA, antibodies against Ro/Sjögren's syndrome $A$ antigen; Anti-La/SSB, antibodies against La/Sjögren's syndrome $B$ antigen; RF, rheumatoid factor. 
Intriguingly, $40.8 \%$ of sera from patients with pSS analysed were positive for IgA anti-CarP antibodies (see online supplementary figure S2) as compared with $26.9 \%$ positive for IgG anti-CarP antibodies. Their presence however, had a lower impact on the outcome of pSS (see online supplementary table $\mathrm{S} 2$ ). Although it is premature to draw definite conclusions, one may speculate that anti-CarP IgGs contribute to pathogenesis while IgAs characterise an 'intermediate' phase in disease development.

In conclusion, this is the first study delineating the presence and frequency of antibodies against carbamylated proteins in association with relevant disease manifestations of pSS. Anti-CarP antibodies were shown to predict the clinical outcome of pSS. It is reasonable to suggest anti-CarP status as an additional biomarker in the serological profile of patients with pSS because of their close association with degree of focal lymphocytic infiltration of the minor salivary glands, formation of ectopic GC-like structures and diminished salivary flow. New serological markers, allowing early detection, could lead to closer patient follow-up and more timely application of immunosuppressive agents. This would limit irreversible tissue damage and reduce mortality related to the comorbidity. ${ }^{49} 50$ Once validated, quantification of anti-CarP antibodies in the serum could be used to determine disease severity and identifying patients at risk of developing additional comorbidity.

\section{Author affiliations \\ ${ }^{1}$ Broegelmann Research Laboratory, Department of Clinical Science, University of Bergen, Bergen, Norway \\ ${ }^{2}$ Department of Clinical Science, University of Bergen, Bergen, Norway \\ ${ }^{3}$ Małopolska Centre of Biotechnology, Jagiellonian University, Krakow, Poland \\ ${ }^{4}$ Department of Clinical Medicine, Centre of Health Science, Federal University of Espírito Santo, Vitoria, Brazil \\ ${ }^{5}$ Department of Rheumatology, Haukeland University Hospital, University of Bergen, Bergen, Norway \\ ${ }^{6}$ Department of Clinical Dentistry, Section for Oral and Maxillofacial Radiology, University of Bergen, Bergen, Norway}

Acknowledgements All authors met the criteria for authorship. BB, CK and AH measured the levels of anti-CarP using ELISA assay. BB and CK acquired and coordinated data for patients with pSS and healthy controls. CK performed univariate and bivariate statistical analyses. MS modelled the multivariate regression analyses and performed partial correlation. DSH collected and supplied the data of the pSS cohort. MVJ analysed the presence of germinal centre formation. VV, VB, $C K, M S, N D, R J, A H$ and PM interpreted the data and CK, ND and PM wrote the manuscript. All authors agreed to publish this work and critically reviewed the article. Conception and design of this work was discussed with all the authors.

Funding This work was funded by grants from the EC Marie Curie ITN (RAPID no. 290246) and (FP7-HEALTH-F3-2012-306029 'TRIGGER'). PM and AH were supported by the grant from the National Science Center (2014/14/E/NZ6/00162, Poland). ND and PM were supported by the Bergen Medical Research Foundation and the Broegelmann Foundation.

\section{Competing interests None declared.}

Ethics approval The Regional Committee of Medical and Health Research Ethics (REK 3.2006.3085) and the Ethics Committee of UFES (407.199/2013).

Provenance and peer review Not commissioned; externally peer reviewed.

Open Access This is an Open Access article distributed in accordance with the Creative Commons Attribution Non Commercial (CC BY-NC 4.0) license, which permits others to distribute, remix, adapt, build upon this work non-commercially, and license their derivative works on different terms, provided the original work is properly cited and the use is non-commercial. See: http://creativecommons.org/ licenses/by-nc/4.0/

\section{REFERENCES}

1 Seo J, Lee KJ. Post-translational modifications and their biological functions: proteomic analysis and systematic approaches. J Biochem Mol Biol 2004;37:35-44.

2 Koro C, Bielecka E, Dahl-Knudsen A, et al. Carbamylation of immunoglobulin abrogates activation of the classical complement pathway. Eur J Immunol 2014;44:3403-12.
3 Jaisson S, Delevallee-Forte $C$, Toure $F$, et al. Carbamylated albumin is a potent inhibitor of polymorphonuclear neutrophil respiratory burst. FEBS Lett 2007;581:1509-13.

4 Holzer M, Birner-Gruenberger R, Stojakovic T, et al. Uremia alters HDL composition and function. J Am Soc Nephrol 2011;22:1631-41.

5 Oimomi M, Hatanaka $\mathrm{H}$, Yoshimura $\mathrm{Y}$, et al. Carbamylation of insulin and its biological activity. Nephron 1987;46:63-6.

6 Kraus LM, Kraus AP Jr. Carbamoylation of amino acids and proteins in uremia. Kidney Int Supp/ 2001;78:S102-7.

7 Apostolov EO, Shah SV, Ok E, et al. Quantification of carbamylated LDL in human sera by a new sandwich ELISA. Clin Chem 2005;51:719-28.

8 Wang Z, Nicholls SJ, Rodriguez ER, et al. Protein carbamylation links inflammation, smoking, uremia and atherogenesis. Nat Med 2007;13:1176-84.

9 Holzer M, Zangger K, El-Gamal D, et al. Myeloperoxidase-derived chlorinating species induce protein carbamylation through decomposition of thiocyanate and urea: novel pathways generating dysfunctional high-density lipoprotein. Antioxid Redox Signal 2012;17:1043-52.

10 Schellekens GA, Visser $H$, de Jong BA, et al. The diagnostic properties of rheumatoid arthritis antibodies recognizing a cyclic citrullinated peptide. Arthritis Rheum 2000;43:155-63.

11 Shi J, Knevel R, Suwannalai P, et al. Autoantibodies recognizing carbamylated proteins are present in sera of patients with rheumatoid arthritis and predict joint damage. Proc Natl Acad Sci USA 2011;108:17372-7.

12 Hissink Muller PC, Anink J, Shi J, et al. Anticarbamylated protein (anti-CarP) antibodies are present in sera of juvenile idiopathic arthritis ( JIA) patients. Ann Rheum Dis 2013;72:2053-5.

13 Shi J, van de Stadt LA, Levarht EW, et al. Anti-carbamylated protein antibodies are present in arthralgia patients and predict the development of rheumatoid arthritis. Arthritis Rheum 2013;65:911-5.

14 Gan RW, Trouw LA, Shi J, et al. Anti-carbamylated Protein Antibodies Are Present Prior to Rheumatoid Arthritis and Are Associated with Its Future Diagnosis. J Rheumatol 2015:42:1-8.

15 Patel R, Shahane A. The epidemiology of Sjögren's syndrome. Clin Epidemiol 2014;6:247-55.

16 Jonsson R, Brun JG. Sjögren's Syndrome, in eLS.John Wiley \& Sons, Ltd, 2001:1-10

17 Kapsogeorgou EK, Christodoulou MI, Panagiotakos DB, et al. Minor salivary gland inflammatory lesions in Sjögren syndrome: do they evolve? J Rheumatol 2013:40:1566-71.

18 Christodoulou MI, Kapsogeorgou EK, Moutsopoulos HM. Characteristics of the minor salivary gland infiltrates in Sjögren's syndrome. J Autoimmun 2010;34:400-7

19 Pepose JS, Akata RF, Pflugfelder SC, et al. Mononuclear cell phenotypes and immunoglobulin gene rearrangements in lacrimal gland biopsies from patients with Sjögren's syndrome. Ophthalmology 1990;97:1599-605.

20 Tobon GJ, Pers JO, Youinou P, et al. B cell-targeted therapies in Sjögren's syndrome. Autoimmun Rev 2010;9:224-8

21 Delaleu N, Nguyen CQ, Peck AB, et al. Sjögren's syndrome: studying the disease in mice. Arthritis Res Ther 2011;13:217.

22 Vitali C, Bombardieri S, Jonsson R, et al. Classification criteria for Sjögren's syndrome: a revised version of the European criteria proposed by the American-European Consensus Group. Ann Rheum Dis 2002;61:554-8.

23 Routsias JG, Tzioufas AG. Autoimmune response and target autoantigens in Sjögren's syndrome. Eur J Clin Invest 2010;40:1026-36.

24 Jonsson $R$, Theander $E$, Sjostrom $B$, et al. Autoantibodies present before symptom onset in primary Sjögren syndrome. Jama 2013;310:1854-5.

25 Kyriakidis NC, Kapsogeorgou EK, Tzioufas AG. A comprehensive review of autoantibodies in primary Sjögren's syndrome: clinical phenotypes and regulatory mechanisms. J Autoimmun 2014:51:67-74.

26 Atzeni F, Sarzi-Puttini P, Lama N, et al. Anti-cyclic citrullinated peptide antibodies in primary Sjögren syndrome may be associated with non-erosive synovitis. Arthritis Res Ther 2008;10:1-6.

27 He J, Qiang L, Ding Y, et al. The role of muscarinic acetylcholine receptor type 3 polypeptide (M3RP205-220) antibody in the saliva of patients with primary Sjögren's syndrome. Clin Exp Rheumatol 2012;30:322-6.

28 Reksten TR, Brokstad KA, Jonsson R, et al. Implications of long-term medication of oral steroids and antimalarial drugs in primary Sjögren's syndrome. Int Immunopharmacol 2011;11:2125-9.

29 Fox Rl, Dixon R, Guarrasi V, et al. Treatment of primary Sjögren's syndrome with hydroxychloroquine: a retrospective, open-label study. Lupus 1996;5(Suppl 1):S31-6.

30 Gottenberg JE, Ravaud P, Puechal X, et al. Effects of hydroxychloroquine on symptomatic improvement in primary Sjögren syndrome: the JOQUER randomized clinical trial. Jama 2014;312:249-58.

31 Fox RI, Chan E, Benton L, et al. Treatment of primary Sjögren's syndrome with hydroxychloroquine. Am J Med 1988;85:62-7.

32 Brito-Zeron $P$, Siso-Almirall A, Bove A, et al. Primary Sjögren syndrome: an update on current pharmacotherapy options and future directions. Expert Opin Pharmacother 2013;14:279-89. 
33 Daniels TE, Cox D, Shiboski $\mathrm{CH}$, et al. Associations between salivary gland histopathologic diagnoses and phenotypic features of Sjögren's syndrome among 1,726 registry participants. Arthritis Rheum 2011;63:2021-30.

34 Peen E, Mellbye OJ, Haga HJ. IgA rheumatoid factor in primary Sjögren's syndrome. Scand J Rheumatol 2009;38:46-9.

35 Klareskog L, Catrina Al, Paget S. Rheumatoid arthritis. Lancet 2009;373:659-72.

36 van der Helm-van Mil AH, Verpoort KN, Breedveld FC, et al. Antibodies to citrullinated proteins and differences in clinical progression of rheumatoid arthritis. Arthritis Res Ther 2005;7:949-58.

37 Bos WH, Wolbink GJ, Boers $M$, et al. Arthritis development in patients with arthralgia is strongly associated with anti-citrullinated protein antibody status: a prospective cohort study. Ann Rheum Dis 2010;69:490-4.

38 Bournia VK, Vlachoyiannopoulos PG. Subgroups of Sjögren syndrome patients according to serological profiles. J Autoimmun 2012;39:15-26.

39 Holzer M, Gauster M, Pfeifer T, et al. Protein carbamylation renders high-density lipoprotein dysfunctional. Antioxid Redox Signal 2011;14:2337-46.

40 Cay HF, Sezer I, Dogan S, et al. Polymorphism in the TNF-alpha gene promoter at position -1031 is associated with increased circulating levels of TNF-alpha, myeloperoxidase and nitrotyrosine in primary Sjögren's syndrome. Clin Exp Rheumatol 2012;30:843-9.

41 Mydel P, Wang Z, Brisslert M, et al. Carbamylation-dependent activation of T cells: a novel mechanism in the pathogenesis of autoimmune arthritis. J Immunol 2010;184:6882-90.

42 Burska AN, Hunt L, Boissinot M. Autoantibodies to posttranslational modifications in rheumatoid arthritis. 2014;2014:492873.
43 Shi J, van de Stadt LA, Levarht EW, et al. Anti-carbamylated protein (anti-CarP) antibodies precede the onset of rheumatoid arthritis. Ann Rheum Dis 2014; 73:780-3.

44 Brink M, Verheul MK, Ronnelid J, et al. Anti-carbamylated protein antibodies in the pre-symptomatic phase of rheumatoid arthritis, their relationship with multiple anti-citrulline peptide antibodies and association with radiological damage. Arthritis Res Ther 2015;17:1-8.

45 Theander E, Manthorpe R, Jacobsson LT. Mortality and causes of death in primary Sjögren's syndrome: a prospective cohort study. Arthritis Rheum 2004;50: 1262-9.

46 Theander E, Vasaitis L, Baecklund E, et al. Lymphoid organisation in labial salivary gland biopsies is a possible predictor for the development of malignant lymphoma in primary Sjögren's syndrome. Ann Rheum Dis 2011;70:1363-8.

47 Risselada AP, Looije MF, Kruize AA, et al. The role of ectopic germinal centers in the immunopathology of primary Sjögren's syndrome: a systematic review. Semin Arthritis Rheum 2013;42:368-76.

48 Jonsson MV, Skarstein K, Jonsson R, et al. Serological implications of germinal center-like structures in primary Sjögren's syndrome. J Rheumatol 2007:34:2044-9.

49 van der Helm-van Mil AH, le Cessie S, van Dongen $\mathrm{H}$, et al. A prediction rule for disease outcome in patients with recent-onset undifferentiated arthritis: how to guide individual treatment decisions. Arthritis Rheum 2007;56:433-40.

50 van Dongen $H$, van Aken J, Lard LR, et al. Efficacy of methotrexate treatment in patients with probable rheumatoid arthritis: a double-blind, randomized, placebo-controlled trial. Arthritis Rheum 2007;56:1424-32. 